\title{
Autoxidation of 2,6-di-tert-butylphenol with cobalt Schiff base catalysts by oxygen in $\mathrm{CO}_{2}$-expanded liquids
}

\author{
Ming Wei, ${ }^{a}$ Ghezai T. Musie, ${ }^{b}$ Daryle H. Busch ${ }^{* b c}$ and Bala Subramaniam ${ }^{a c}$ \\ a Department of Chemical and Petroleum Engineering, The University of Kansas, Lawrence, KS \\ 66045-2223, USA \\ ${ }^{b}$ Department of Chemistry, The University of Kansas, Lawrence, KS 66045-2223, USA \\ c Center for Environmentally Beneficial Catalysis, The University of Kansas, Lawrence, KS, USA
}

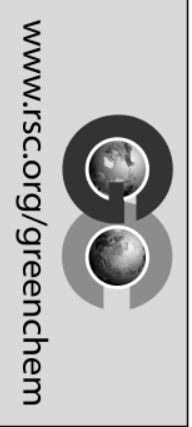

Received 1st September 2003, Accepted 19th January 2004

First published as an Advance Article on the web 4th February 2004

\begin{abstract}
$\mathrm{CO}_{2}$-expanded acetonitrile and methylene chloride have been used in this first detailed study of catalytic $\mathrm{O}_{2}$ oxidations in these remarkably effective reaction media. The autoxidation of 2,6-di-tert-butylphenol (DTBP) with the cobalt Schiff-base ( $\mathrm{Co}$ (salen*) in these so-called $\mathrm{CO}_{2}$-expanded liquids (CXLs) has been extensively studied using precisely controlled and monitored batch reactions. The dependence of conversion, selectivity and turn-over-frequency on various reaction parameters, including temperature, $\left[\mathrm{O}_{2}\right]$, [catalyst], and solvent composition has been evaluated. The rates of $\mathrm{O}_{2}$-oxidation in CXLs are typically 1-2 orders of magnitude greater than those obtained with either the neat organic solvent or supercritical $\mathrm{CO}_{2}$ as reaction media. In keeping with the proposed mechanism, the dependence of both the selectivity and conversion on $\mathrm{O}_{2}$ concentration and catalyst concentration indicates that the $\mathrm{O}_{2}$ adduct, and not free $\mathrm{O}_{2}$, serves as oxidant in two critical steps in these systems. The increase in conversion with increasing temperature supports formation of the phenoxy radical as the rate determining step. In contrast, the temperature independence of selectivity is as expected for two competing radical coupling reactions. The balance between $\mathrm{O}_{2}$ solubility and mixed-solvent dielectric constant determines some of the benefits of the CXLs. Because of the greatly increased solubility of $\mathrm{O}_{2}$ in CXLs, the conversion in those media is substantially greater than that in either $s c \mathrm{CO}_{2}$ or the neat organic solvent. However, conversion eventually decreases with increasing $\mathrm{CO}_{2}$ content of the solvent because of the decreasing dielectric constant of the medium. The solubilities of $\mathrm{O}_{2}$ and $\mathrm{Co}$ (salen*) have been determined in CXLs based on methylene chloride.
\end{abstract}

\section{Introduction}

This work exploits the beneficial chemical and physical properties of mixed solvents containing liquid $\mathrm{CO}_{2}$ (abbreviated CXLs) to perform homogeneous catalytic oxidations. CXLs are produced by condensing relatively large amounts of sub-critical $\mathrm{CO}_{2}$ into fixed amounts of an organic solvent. Each $\mathrm{CO}_{2}$-expanded solvent may, in principle, generate a continuum of media ranging from the neat organic solvent to neat $\mathrm{CO}_{2}$. Thus, the solvent properties may be varied to accommodate contrasting solubilities simultaneously, like those of permanent gases $\left(\mathrm{O}_{2}, \mathrm{H}_{2}\right.$ and $\left.\mathrm{CO}\right)$ and homogeneous catalysts based on metallic elements. A large amount of $\mathrm{CO}_{2}$ favors oxygen solubility and polar organic solvents favor metal catalyst solubility. CXLs have been exploited for performing homogenous catalysis, including hydrogenations, ${ }^{1 a-c}$ oxidations, ${ }^{1 d-f}$ and hydroformylations. ${ }^{1 g}$ In the referenced applications, dense phase $\mathrm{CO}_{2}$ is partnered with a variety of solvents such as methanol, ${ }^{1 a}$ acetonitrile, ${ }^{1 d, e}$ and ionic liquids. ${ }^{1 c, f, g}$

Reactions in CXLs benefit both in terms of improved behavior of the fundamental chemical processes and potential benefits to the environment as shown elsewhere. ${ }^{1 d, e}$

Reaction advantages of CXLs:

- higher oxygen miscibility (as much as two orders of magnitude) compared to organic solvents

- adequate solubility of transition metal catalysts without such ligand modifications as the use of environmentally deleterious fluorination

- enhanced turnover frequencies

- comparable or better product selectivities than in neat organic solvent or $s c \mathrm{CO}_{2}$

- facile catalyst separation following the reaction cycle, by adding more $\mathrm{CO}_{2}$ and adjusting the temperature

Environmental and economic advantages:

- substantial (up to $\sim 80 \mathrm{vol} \%$ ) replacement of organic solvents with dense-phase $\mathrm{CO}_{2}$
- milder process pressure (tens of bars) compared to $s c \mathrm{CO}_{2}$ (hundreds of bars)

- operation with $\mathrm{CO}_{2}$-based media in the near-critical region (where the specific heat increases with isothermal pressure increases) lessens the risk of reaction runaway and explosions ${ }^{2}$

- enhanced reaction rates and low process pressures yield process economics that are favorable over those for $\mathrm{scCO}_{2}$

As reviewed elsewhere, ${ }^{1 d, 3}$ homogeneous "green" oxidation in $s c \mathrm{CO}_{2}$ as the solvent, has been the focus of many investigations. Carbon dioxide is non-toxic, not subject to oxidation, nonflammable, inexpensive, recyclable and has a relatively low critical temperature $\left(31.1{ }^{\circ} \mathrm{C}\right)$ and moderate critical pressure (73.8 bar). The application of $\mathrm{CO}_{2}$ in catalytic chemistry and reaction engineering satisfies several of the green chemistry and engineering principles. ${ }^{4}$ For instance, dense phases of $\mathrm{CO}_{2}$ are considered benign alternatives to traditional organic solvents. Further, since traditional organic solvents will always emit their vapors, replacement with $\mathrm{CO}_{2}$ represents pollution prevention. Further, the toxicity of $\mathrm{CO}_{2}$ is lower than those of many organic solvents and $\mathrm{CO}_{2}$ is abundantly available.

During the last decade, many of the advantages of $s c \mathrm{CO}_{2}$ have been demonstrated for chemical reactions on a laboratory scale. While it is recognized that performing catalytic reactions in $s c \mathrm{CO}_{2}$ offers maximum environmental benefit, there exist major barriers impeding the application of $\mathrm{CO}_{2}$ in industrial chemical processes. In many cases, $s c \mathrm{CO}_{2}$-based homogeneous catalytic reactions are limited by inadequate solubilities of preferred homogeneous catalysts. In addition, $\mathrm{CO}_{2}$ is non-polar with a non-tunable dielectric constant, which usually results in lower reaction rates compared to those attained with conventional organic solvents. Furthermore, high process pressures (hundreds of bars) are required in most reported applications. This combination of high pressures and low reaction rates clearly does not favor process economics.

We report here a systematic study of homogeneous catalytic oxidation of 2,6-di-tert-butylphenol (DTBP) by molecular oxygen 
in $\mathrm{CO}_{2}$-expanded solvent media, CXLs, using cobalt(II) Schiff base complexes as catalysts. This reaction has been studied well in both heterogeneous ${ }^{5}$ and homogeneous ${ }^{6}$ systems, as well as in $s c \mathrm{CO}_{2}{ }^{7}$ DTBP is converted to a mixture of 2,6-di-tert-butyl-1,4-benzoquinone (DTBQ) and the related product of radical coupling, 3,5,3',5'tetra-tert-butyl-4,4'-diphenoquinone (TTDBQ).

Scheme 1 shows the mechanism proposed for this reaction in most media. The first step is rate determining and involves $\mathrm{O}_{2}+\mathrm{LCo} \rightleftharpoons \mathrm{LCoOO}$.
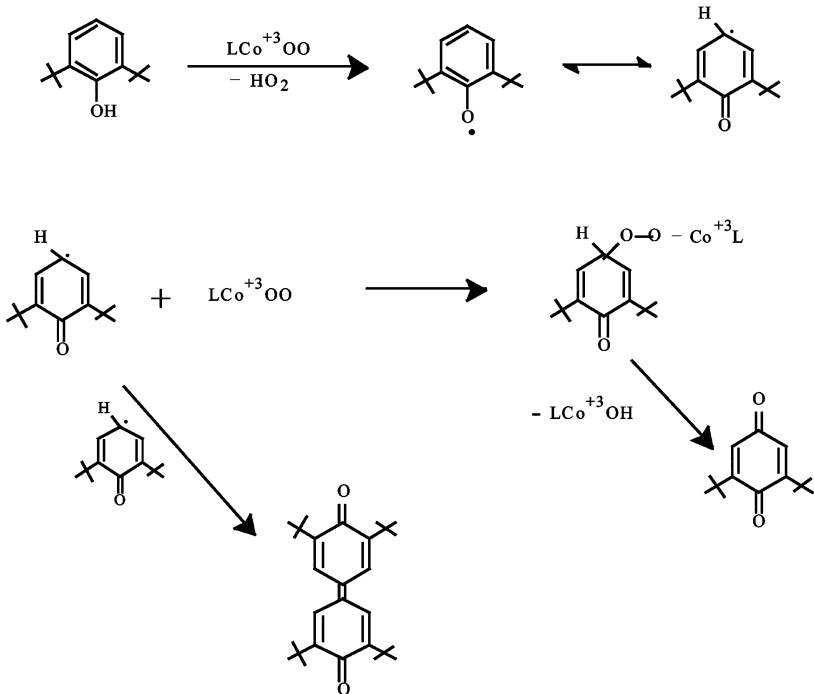

Scheme 1 The broadly accepted mechanism for the oxidation of 2,6-ditert-butyl phenol by Schiff base cobalt catalysts: $\mathrm{Co}\left(\right.$ salen*) $^{*}$ and $\mathrm{Co}(\mathrm{sa}-$ len).

conversion of phenol to the phenoxy radical by the oxygen adduct of the catalyst $\left[\mathrm{Co}(\right.$ salen* $\left.) \mathrm{O}_{2}\right]$. Subsequently, two parallel reactions compete: capture of the phenoxy radical by a second mole of the oxygen adduct leads to DTBQ, the desired product; the coupling of two phenoxy radicals ultimately yields TTDBQ. In the work that follows, we specifically address the following questions:

1. How do the efficacies of the reactions in CXLs compare with those in $s c \mathrm{CO}_{2}$ or neat organic solvent?

2. How do the operating variables (pressure, temperature, and extent of solvent replacement by $\mathrm{CO}_{2}$ ) affect the turnover frequency and product selectivity?

3. How does the mechanism of the $\mathrm{O}_{2}$ oxidation reaction change in going from $s c \mathrm{CO}_{2}$ or neat organic solvent to CXLs?

4. How does the replacement of an organic solvent by CXLs affect catalyst and oxygen solubilities?

Methylene chloride and acetonitrile are employed as solvents that are expanded by carbon dioxide to provide the new reaction media, CXLs. Our previous studies of this reaction system in $\mathrm{CO}_{2-}$ expanded acetonitrile ${ }^{1 e}$ and in $s c \mathrm{CO}_{2}{ }^{7}$ provide the bases for comparison.

\section{Experimental section}

\section{Apparatus}

The experimental units and procedures for measuring the solubilities of oxygen and of the catalyst complexes in $\mathrm{CO}_{2}$-expanded solvents, including safety features and analytical methods for measuring $\mathrm{O}_{2}$ concentrations, are described in detail elsewhere. ${ }^{1 d, e, 7}$ The catalytic oxidation studies, including conversion and selectivity measurements, were performed in specially constructed batch view cells as described elsewhere.?

\section{Materials}

HPLC grade $\mathrm{CH}_{3} \mathrm{CN}$ and $\mathrm{CH}_{2} \mathrm{Cl}_{2}$, and the catalysts, [ $\left\{N, N^{\prime}-\right.$ $\mathrm{Bis}(3,5$-di-tert-butylsalicylidene)1,2-cyclohexanediaminato-
$(2-)\}$ cobalt(II) $], \quad\left\{\right.$ i.e., $\mathrm{Co}\left(\right.$ salen $\left.\left.^{*}\right)\right\}$, and, $\left[\left\{N, N^{\prime}\right.\right.$-Bis(salicylidene)1,2-cyclohexanediaminato(2-)\}cobalt(II)], \{i.e., Co(salen)\}, were purchased from Aldrich Chemical Co., Inc., and used without further treatment. The substrate 2,6-di-tert-butylphenol (DTBP) was purchased from Aldrich Chemical Co., Inc., and recrystallized from hexane. Methylimidazole and toluene were purchased from Fisher Scientific and used as received. Coolant grade liquid $\mathrm{CO}_{2}$, in cylinders with dip tubes, and cylinders of ultra high purity oxygen were purchased from Air Products and Chemicals, Inc.

\section{Results and discussion}

\section{Oxidation of substituted phenols by transition metal complexes}

Previous studies in these laboratories provided strong support for the mechanism given in Scheme 1 for the $\mathrm{O}_{2}$ oxidation of DTBP in $s c \mathrm{CO}_{2}$ as the solvent and using $\mathrm{Co}\left(\right.$ salen $\left.^{*}\right)$ for the catalyst. ${ }^{7}$ The same reaction has now been studied in two families of CXLs using precisely controlled and monitored batch reactions. The influences of reaction parameters (oxygen concentration, catalyst concentration, reaction temperature, and expansion ratio) on DTBP conversion and DTBQ selectivity during the oxidation reaction were determined. The fixed values of the operating parameters are as follows: catalyst concentration, $0.416 \mathrm{mM}$; reaction temperature, $60{ }^{\circ} \mathrm{C}$; reaction time, $2 \mathrm{~h}$; catalyst : substrate : $\mathrm{O}_{2}$ mole ratio, $1: 80$ : 800; expansion fold $\left(\mathrm{V} / \mathrm{V}_{0}\right)$,2; mole ratio of methyl imidazole to catalyst 1.28; solvent, $\mathrm{CH}_{3} \mathrm{CN}$; effective reaction volume, $10 \mathrm{~mL}$. In a given set of experiments, any of these parameters may be chosen as a reaction variable.

Fig. 1 shows that the DTBP conversion and DTBQ selectivity remain virtually constant when the $\left[\mathrm{O}_{2}\right]$ increases from $33.3 \mathrm{mM}$ to

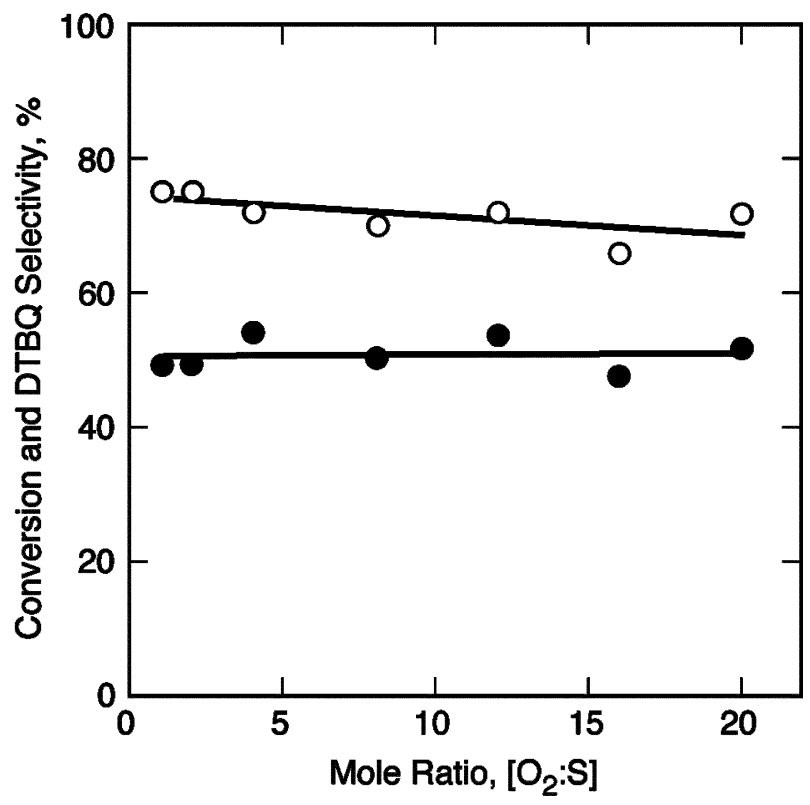

Fig. 1 Effect of $\mathrm{O}_{2}$ concentration on DTBP $(-)$ conversion and DTBQ selectivity $(\mathrm{O})$ in $\mathrm{CO}_{2}$-expanded $\mathrm{CH}_{3} \mathrm{CN}$. Reaction conditions: catalyst $\left[\mathrm{Co}\left(\right.\right.$ salen $\left.\left.^{*}\right)\right]$ concentration $=0.416 \mathrm{mM}$; reaction time $=2 \mathrm{~h}$; reaction temperature $=60{ }^{\circ} \mathrm{C}$; DTBP: catalyst mole ratio $=1: 80$; expansion ratio $\left(V / V_{0}\right)=2$; volume of methyl imidazole $=2 \mu \mathrm{L}$.

$667 \mathrm{mM}$. A different behavior is observed in $s c \mathrm{CO}_{2}{ }^{7}$ where the DTBP conversion and DTBQ selectivity increase linearly with the oxygen concentration for $\left[\mathrm{O}_{2}\right] /[\mathrm{DTBP}]$ ratios less than 100 , and only reach saturation for greater values of this ratio. The obvious conclusion in both cases is that free oxygen does not contribute to the reactions that determine the conversion and selectivity of these systems. It follows that the cobalt oxygen complex, [Co(salen*) $\mathrm{O}_{2}$ ], and not $\mathrm{O}_{2}$, is the reagent responsible for the initial oxidation, producing the phenoxy radical, and that the only pathway leading to DTBQ formation is the radical coupling 
between the phenoxy radical and $\left[\mathrm{Co}\left(\right.\right.$ salen*) $\left.\mathrm{O}_{2}\right] \cdot{ }^{7}$ Because $\mathrm{O}_{2}$ is totally miscible in $s c \mathrm{CO}_{2}$, the observed saturation behavior in CXLs at much lower $\left[\mathrm{O}_{2}\right] /\left[\right.$ DTBP] ratios cannot be attributed to $\mathrm{O}_{2}$ solubility considerations. However, it seems plausible that the higher dielectric constant in this CXL (due to the presence of acetonitrile) may stabilize $\left[\mathrm{Co}\left(\right.\right.$ salen $\left.\left.^{*}\right) \mathrm{O}_{2}\right]$ at lower $\mathrm{O}_{2}$ concentrations compared to $s c \mathrm{CO}_{2}$, which has a very low dielectric constant. The binding of $\mathrm{O}_{2}$ to cobalt(II) formally constitutes a redox process producing cobalt(III) and the bound superoxide ion, a highly polar grouping. ${ }^{8}$ Because it is the oxygen adduct, $\left[\mathrm{Co}\left(\operatorname{salen}^{*}\right) \mathrm{O}_{2}\right]$, that oxidizes DTBP to the phenoxy radical and, subsequently, oxidizes that radical to DTBQ, its abundance determines two of the three important reaction rates. (The third reaction is radical-radical coupling between phenoxy radicals.) Therefore, the presence of excess free $\mathrm{O}_{2}$ is not expected to significantly influence conversion rates and product distribution.

In Fig. 2, the DTBP conversion and DTBQ selectivity are shown as functions of reaction temperature in fixed-time, batch studies.

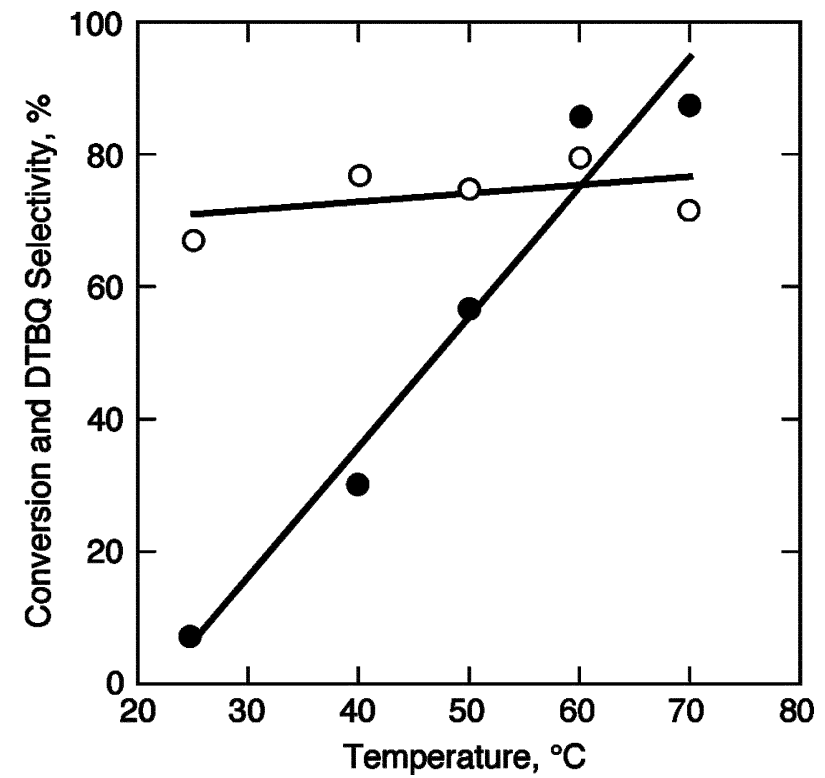

Fig. 2 Effect of temperature on DTBP conversion (O) and DTBQ selectivity (O)in $\mathrm{CO}_{2}$-expanded $\mathrm{CH}_{3} \mathrm{CN}$. Reaction conditions: catalyst $[\mathrm{Co}($ salen $*)]$ concentration $=0.25 \mathrm{mg} \mathrm{mL}^{-1}$; reaction time $=2 \mathrm{~h}$; catalyst : substrate : $\mathrm{O}_{2}$ mole ratio $=1: 80: 800$; expansion fold $\left(V / V_{0}\right)=2$; volume of methyl imidizole $=2 \mu \mathrm{L}$

The DTBP conversion increased monotonically from $10 \%$ to approximately $90 \%$ when the temperature was increased from 25 ${ }^{\circ} \mathrm{C}$ to $70{ }^{\circ} \mathrm{C}$, while the DTBQ selectivity remained virtually constant at $\sim 75 \%$. The constant DTBQ selectivity with increasing temperature is similar to that reported previously for this reaction system in $s c \mathrm{CO}_{2}$ medium. The mechanism commonly attributed to this reaction in other media ${ }^{6}$ (Scheme 1 ) is entirely consistent with the behavior just described for the reaction conducted in a CXL. The pathways to both products begin with the formation of a common radical, the phenoxy radical, which appears to be the rate determining event. Selectivity is determined by competition between oxygenation of the first-formed radical and its dimerization. Because the activation energy is very low for radical reactions, one would not expect the product distribution to change with temperature. Thus, the mechanism given in Scheme 1 is appropriate for this reaction in both $s c \mathrm{CO}_{2}$ and CXLs.

The influence of catalyst concentration on the DTBP conversion and DTBQ selectivity is shown in Fig. 3. As expected, the DTBP conversion increases with increasing catalyst concentration and reaches its highest value of $85 \%$ at a catalyst concentration of 1.3 $\mathrm{mM}$, above which the catalyst precipitates and the reaction no longer occurs in a homogeneous phase. Similarly, the DTBQ selectivity increases with increasing catalyst concentration. In both

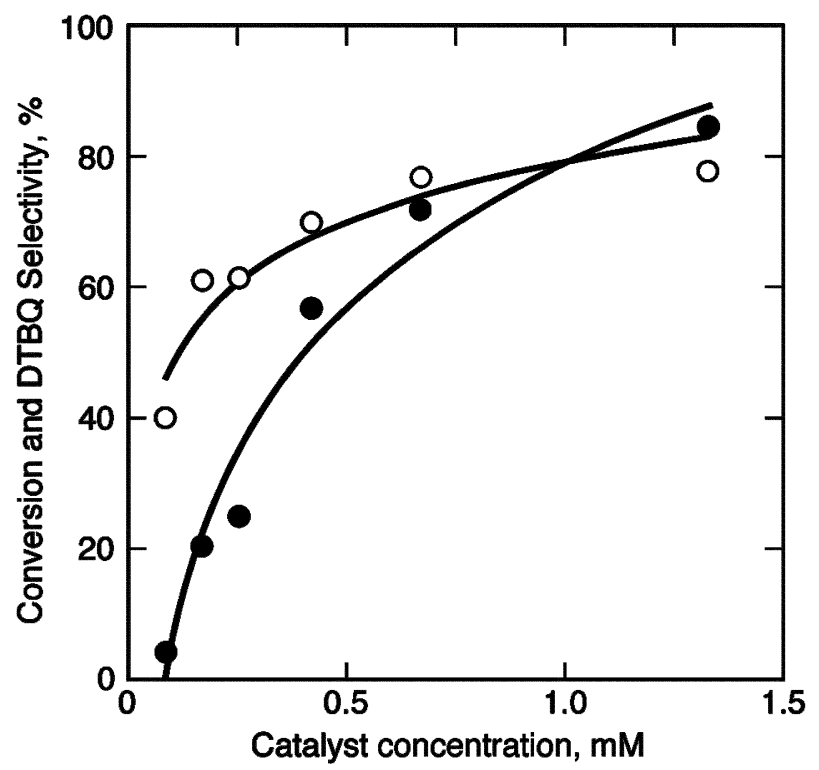

Fig. 3 Effect of catalyst $\left[\mathrm{Co}\left(\right.\right.$ salen*$\left.\left.^{*}\right)\right]$ concentration on DTBP conversion (O) and DTBQ selectivity $(O)$ in $\mathrm{CO}_{2}$-expanded $\mathrm{CH}_{3} \mathrm{CN}$. Reaction conditions: reaction time $=2 \mathrm{~h}$; reaction temperature $=60^{\circ} \mathrm{C}$; substrate : $\mathrm{O}_{2}$ mole ratio $=1: 10$; expansion ratio $\left(V / V_{0}\right)=2$; volume of methyl imidizole $=2 \mu \mathrm{L}$

cases, the concentration dependence resembles that commonly observed for saturation processes. This behavior is different than the reported observation for the same reaction system in $s c \mathrm{CO}_{2}$, where the selectivity was independent of catalyst concentration. This may be attributed to the lower concentration of $\mathrm{O}_{2}$ in CXLs, compared to $s c \mathrm{CO}_{2}$, in which the oxygen is completely miscible with the solvent. Under the conditions of the previously reported experiments in $s c \mathrm{CO}_{2}$, the catalyst is converted entirely to the oxygen adduct at all catalyst concentrations studied; i.e., the adduct formation equilibrium is always saturated. In contrast, because of the lower $\mathrm{O}_{2}$ concentration in CXLs, the concentration of the oxygen complex, $\left[\mathrm{Co}\left(\right.\right.$ salen*$\left.^{*} \mathrm{O}_{2}\right]$, increases with catalyst concentration. Because the product distribution is determined by competition between the oxidation of the phenoxy radical and its dimerization, higher concentrations of $\left[\mathrm{Co}\left(\right.\right.$ salen $\left.\left.^{*}\right) \mathrm{O}_{2}\right]$ favor the formation of DTBQ.

The $\mathrm{O}_{2}$ concentration, the transport properties (diffusivity and viscosity) and the dielectric constant may be tuned in CXLs by simply manipulating the $\mathrm{CO}_{2}$ fraction. With increasing $\mathrm{CO}_{2}$ content, the $\mathrm{O}_{2}$ solubility increases. ${ }^{1 e} \mathrm{We}$ speculate that the mobility of the radicals increases with $\mathrm{CO}_{2}$ content in CXLs while the dielectric constant decreases, all relative to the neat organic solvent. Decreased dielectric constant may decrease the stability of the $\mathrm{O}_{2}$ adduct, $\left[\mathrm{Co}(\right.$ salen* $\left.) \mathrm{O}_{2}\right]$, and increased mobility (and collisions) may cause more rapid coupling between pairs of phenoxy radicals. Thus several complicating factors add complexity to conversion and product selectivity. Fig. 4 depicts the DTBP conversion and DTBQ selectivity in CXLs at various levels of expansion. The DTBP conversion decreases with increasing levels of expansion. The reduced dielectric constant at greater levels of expansion with $\mathrm{CO}_{2}$ hinders DTBP conversion because of the highly polar transition state for the rate determining step. The opposite trend in the case of DTBQ selectivity, which increases moderately with increasing levels of expansion, can be attributed to two factors. The increased $\mathrm{CO}_{2}$ content increases the oxygen concentration in the liquid phase, thereby converting more of the catalyst into the $\mathrm{O}_{2}$ adduct, and as discussed above, that favors DTBQ formation. Further, the retarded rate of conversion is, in fact, a decrease in the rate of production of phenoxy radicals, and that works against the undesirable phenoxy radical coupling reaction. The expected enhancement of transport rates with increased $\mathrm{CO}_{2}$ content does not enter into these explanations. Fundamental studies of the variations of dielectric constant and transport properties of 


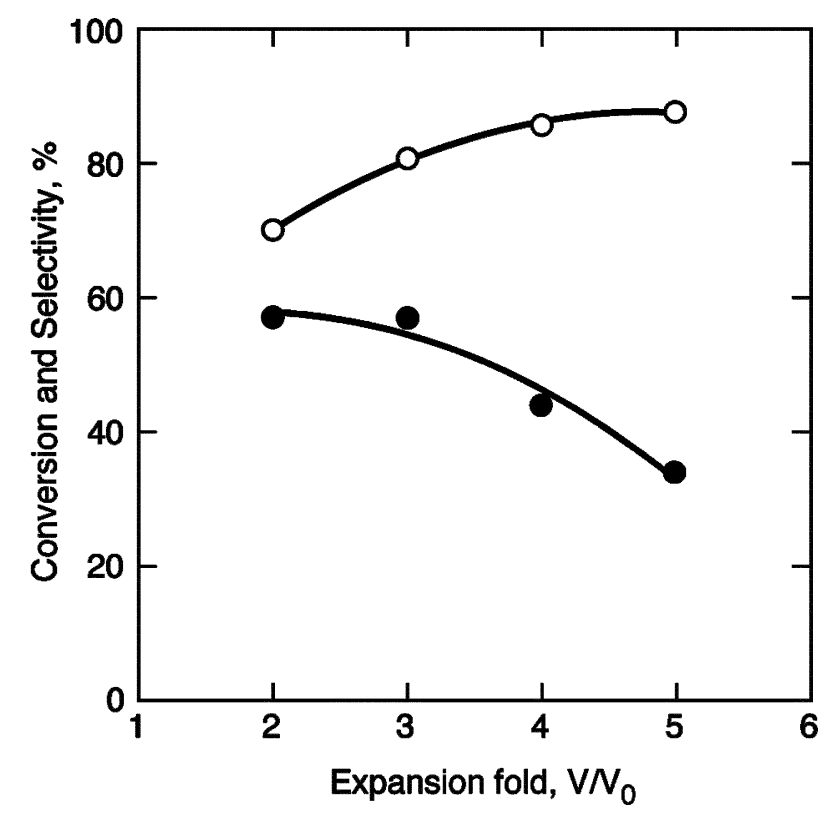

Fig. 4 Effect of solvent expansion by $\mathrm{CO}_{2}$ on DTBP conversion $(-)$ and DTBQ selectivity $(\mathrm{O})$ in $\mathrm{CO}_{2}$-expanded $\mathrm{CH}_{3} \mathrm{CN}$. Reaction conditions: catalyst $\left[\mathrm{Co}\left(\right.\right.$ salen $\left.\left.^{*}\right)\right]$ concentration $=0.25 \mathrm{mg} \mathrm{mL}^{-1}$; reaction time $=2 \mathrm{~h}$; reaction temperature $=60{ }^{\circ} \mathrm{C}$; catalyst : substrate $: \mathrm{O}_{2}$ mole ratio $=1: 80$ : 800 ; volume of methyl imidizole $=2 \mu \mathrm{L}$.

CXLs, and their effects on the concentrations of various species are needed to develop a better understanding of the observed effects.

\section{Comparison of turnover frequencies in different reaction media}

The physicochemical properties of CXLs may be tuned, not only by varying the proportion of the $\mathrm{CO}_{2}$ relative to the chosen organic solvent (as explained above), but also by varying the organic solvent itself. To better understand solvent effects, we compared the DTBP oxidation in different reaction media as follows: neat $\mathrm{CH}_{3} \mathrm{CN}, \quad s c \mathrm{CO}_{2}, \mathrm{CO}_{2}$-expanded $\mathrm{CH}_{3} \mathrm{CN}$, and $\mathrm{CO}_{2}$-expanded $\mathrm{CH}_{2} \mathrm{Cl}_{2}$. The reaction conditions are as follows: catalyst concentration, $0.415 \mathrm{mM}$; reaction time, $2 \mathrm{~h}$; catalyst : substrate : $\mathrm{O}_{2}$ mole ratio, $1: 80: 800$; expansion $\left(V / V_{0}\right), 2$; mole ratio of methyl imidizole to catalyst, 1.28 ; effective reaction volume, $10 \mathrm{~mL}$.

Fig. 5 compares the turnover frequency (TOF) (defined as the moles of DTBP converted per mole of catalyst per hour) as a function of reaction temperature in the different reaction media. The TOFs in $\mathrm{CO}_{2}$-expanded solvent media $\left(V / V_{0}=2 ; p=60-90\right.$ bars) are between one and two orders of magnitude greater than in $s c \mathrm{CO}_{2}\left(p=207\right.$ bar) or neat $\mathrm{CH}_{3} \mathrm{CN}$. Among the CXLs, higher TOF numbers are obtained for the DTBP oxidation in $\mathrm{CO}_{2^{-}}$ expanded $\mathrm{CH}_{3} \mathrm{CN}$ than for those in $\mathrm{CHCl}_{2}$. As shown in Fig. 6, although the TOFs in CXLs are one to two orders of magnitude higher than that in $s c \mathrm{CO}_{2}$, the DTBQ selectivity is more or less similar for all dense $\mathrm{CO}_{2}$ phases, increasing moderately with reaction temperature. In comparison to DTBQ selectivity obtained in various organic solvents, ${ }^{1 d}$ higher DTBQ selectivity is observed in $s c \mathrm{CO}_{2}$ and CXLs. It is not uncommon to observe "ignition" or step-type temperature dependence during oxidation reactions as we do in the case of the $\mathrm{CO}_{2}$-expanded $\mathrm{CH}_{2} \mathrm{Cl}_{2}$. The reasons for the differing temperature dependence in the various CXLs are not fully understood as yet. Ongoing mechanistic investigations should provide a better understanding in this regard.

The common inexpensive $\mathrm{Co}$ (salen) catalyst is insoluble in $s c \mathrm{CO}_{2}$ and shows no detectable activity as a DTBP oxidation catalyst in that medium. In sharp contrast, Co(salen) shows remarkable activity in $\mathrm{CO}_{2}$-expanded $\mathrm{CH}_{3} \mathrm{CN}$. As shown in Fig. 7, the DTBP conversion increased from less than $5 \%$ to around $40 \%$ as the temperature increased from $25^{\circ} \mathrm{C}$ to $70{ }^{\circ} \mathrm{C}$, while the DTBQ selectivity increased from $60 \%$ to $70 \%$ over the same temperature range. This example demonstrates an important advantage of

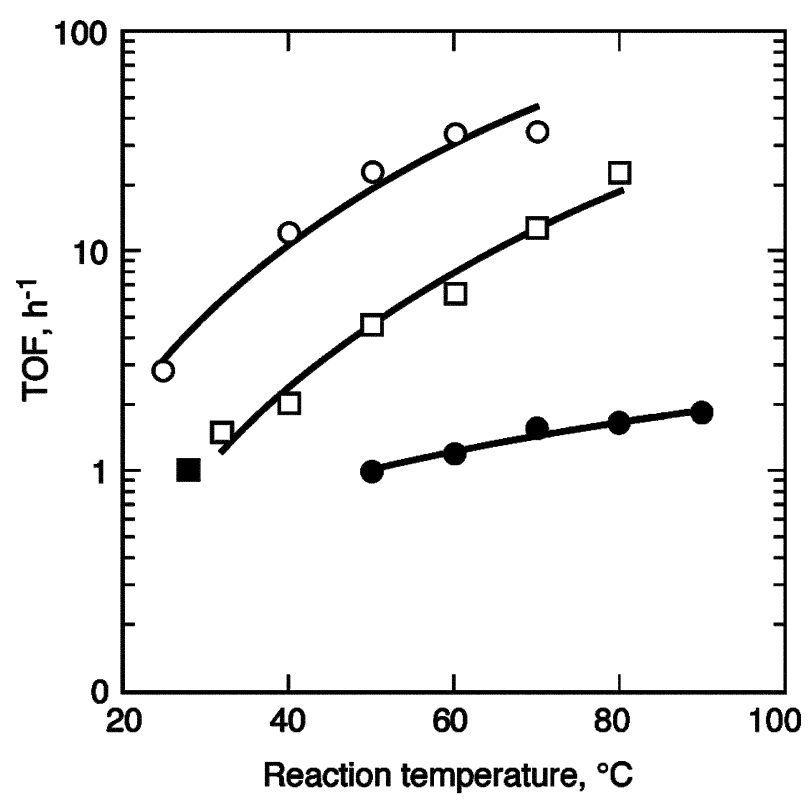

Fig. 5 Effect of temperature on turnover frequencies (TOFs) for 2,6-ditert-butyl phenol oxidation with $\mathrm{Co}\left(\mathrm{Salen}^{*}\right)$ catalysts in supercritical $\mathrm{CO}_{2}$ (O), neat $\mathrm{CH}_{3} \mathrm{CN}(\mathbf{\square}), \mathrm{CO}_{2}$-expanded $\mathrm{CH}_{3} \mathrm{CN}(\mathrm{O})$, and $\mathrm{CO}_{2}$-expanded $\mathrm{CH}_{2} \mathrm{Cl}_{2}$ ( $\square$ ). Reaction conditions: total pressure = 1 bar (in neat solvent); 207 bar (in $s c \mathrm{CO}_{2}$ ) and 50-90 bar (in $\mathrm{CO}_{2}$-expanded solvent depending on reaction temperature); Catalyst concentration $=0.25 \mathrm{mg} \mathrm{mL}^{-1}$; catalyst : substrate $: \mathrm{O}_{2}$ mole ratio $=1: 80: 800$; volume of methyl imidizole $=2$ $\mu \mathrm{L} ; V / V_{0}=2$ (in the case of $\mathrm{CO}_{2}$-expanded solvent media); reaction volume $=10 \mathrm{~mL}$.

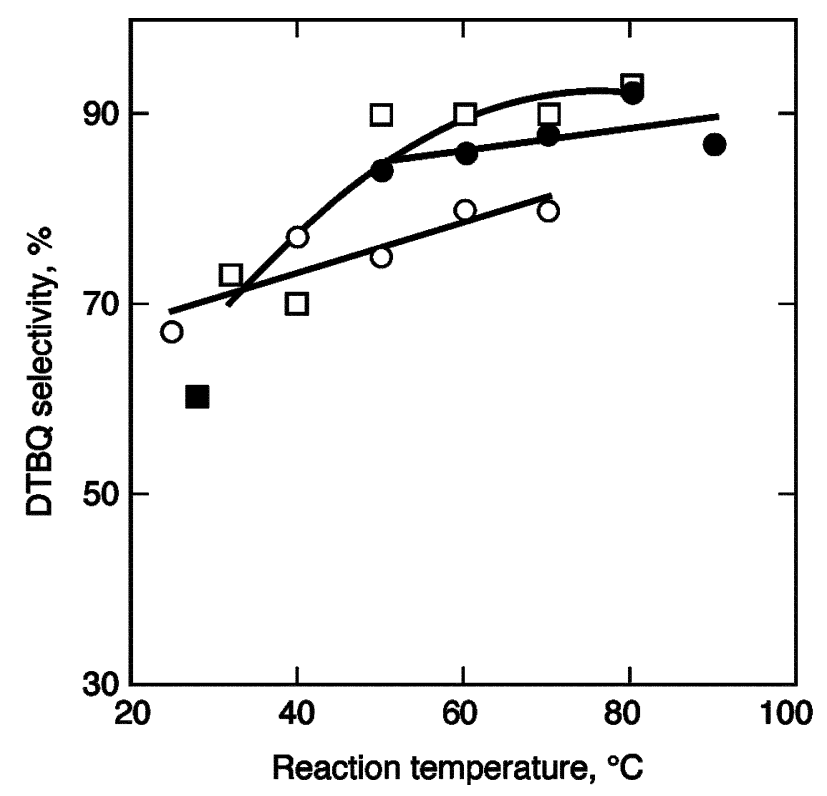

Fig. 6 Influence of reaction temperature on DTBQ selectivity during 2,6-di-tert-butyl phenol oxidation with $\mathrm{Co}$ (salen*) catalyst in supercritical $\mathrm{CO}_{2}(\mathbf{O})$, neat $\mathrm{CH}_{3} \mathrm{CN}(\boldsymbol{\bullet}), \mathrm{CO}_{2}$-expanded $\mathrm{CH}_{3} \mathrm{CN}(\mathrm{O})$, and $\mathrm{CO}_{2}$-expanded $\mathrm{CH}_{2} \mathrm{Cl}_{2}$ ( $\square$ ). Reaction conditions: total pressure $=1$ bar (in neat solvent); 207 bar (in $s c \mathrm{CO}_{2}$ ) and 50-90 bar (in $\mathrm{CO}_{2}$-expanded solvent depending on reaction temperature); Catalyst concentration $=0.25 \mathrm{mg} \mathrm{mL}^{-1}$; catalyst : substrate : $\mathrm{O}_{2}$ mole ratio $=1: 80: 800$; volume of methyl imidizole $=2$ $\mu \mathrm{L} ; V / V_{0}=2$ (in the case of $\mathrm{CO}_{2}$-expanded solvent media); reaction volume $=10 \mathrm{~mL}$.

CXLs. Because most conventional solvents are expanded by $\mathrm{CO}_{2}$, it is possible to dissolve most homogeneous transition metal catalysts in CXLs containing an appropriate solvent. In contrast, most unmodified transition metal complexes have inadequate solubilities in $s c \mathrm{CO}_{2}$. These results clearly show that $\mathrm{CO}_{2^{-}}$ expanded solvents complement $s c \mathrm{CO}_{2}$ as reaction media by broadening the range of conventional catalyst + solvent combinations with which homogeneous $\mathrm{O}_{2}$-based oxidations can be performed. 


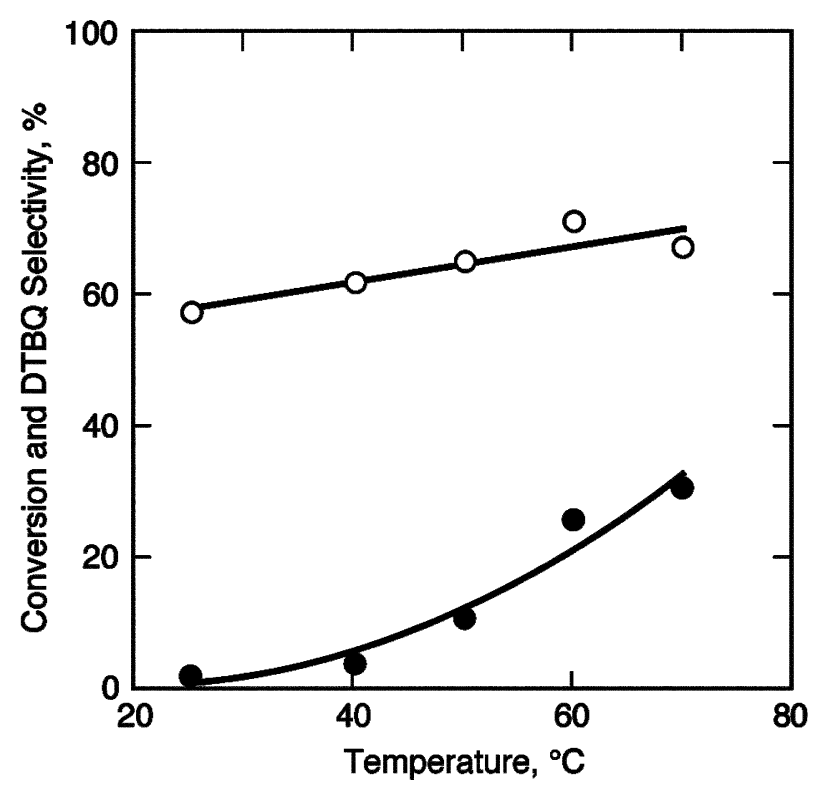

Fig. 7 Effect of reaction temperature on DTBP conversion $(-)$ and DTBQ selectivity $(\mathrm{O})$ during DTBP oxidation by $\mathrm{O}_{2}$ in $\mathrm{CO}_{2}$-expanded $\mathrm{CH}_{3} \mathrm{CN}$. Reaction conditions: catalyst $[\mathrm{Co}($ salen $)]$ concentration $=0.25 \mathrm{mg} \mathrm{mL}^{-1}$; reaction time $=2 \mathrm{~h}$; catalyst $:$ substrate $: \mathrm{O}_{2}$ mole ratio $=1: 80: 800$ expansion fold $\left(V / V_{0}\right)=2$; volume of methyl imidizole $=2 \mu \mathrm{L}$.

\section{Influence of $\mathrm{CO}_{2}$-addition on solubility of $\mathrm{Co}\left(\mathrm{salen}^{*}\right)$ in CXLs}

Adding $\mathrm{CO}_{2}$ to $\mathrm{CO}_{2}$-miscible solvents "expands" the solvent volume as the $\mathrm{CO}_{2}$ pressure is increased. However, the solubilities of polar solutes in CXLs decrease upon $\mathrm{CO}_{2}$ addition. We investigated the effect of isothermal $\mathrm{CO}_{2}$ addition on solutions of catalyst in organic solvents. Fig. 8 shows isothermal volumetric

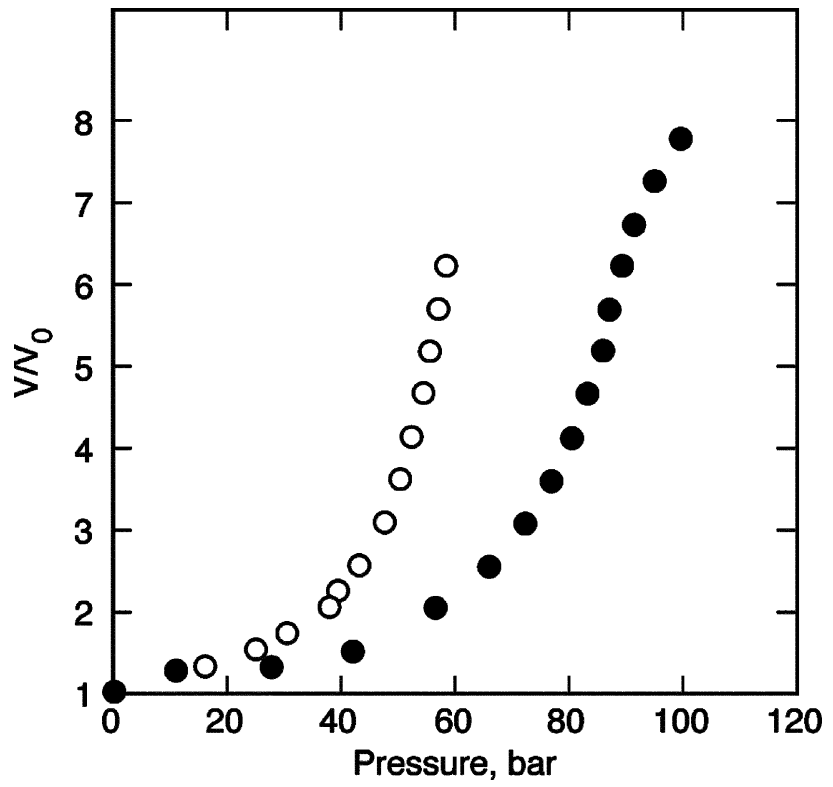

Fig. 8 Volumetric expansion of $\mathrm{Co}(\mathrm{Salen} *)+\mathrm{CH}_{2} \mathrm{Cl}_{2}$ solution $(0.419$ $\mathrm{mM})$ by $\mathrm{CO}_{2}$ at $25^{\circ} \mathrm{C}(\mathrm{O})$ and $50{ }^{\circ} \mathrm{C}$

expansion profiles at $25^{\circ} \mathrm{C}$ and $50^{\circ} \mathrm{C}$ for the catalyst $\left[N, N^{\prime}\right.$-Bis $(3,5$ di-tert-butylsalicylidene)1,2-cyclohexanediaminato(2-)]cobalt(II) (abbreviated $\mathrm{Co}\left(\right.$ salen*)) in $\mathrm{CH}_{2} \mathrm{Cl}_{2}(0.415 \mathrm{mM})$. As expected, higher pressures are required at higher temperatures to reach the same expansion level. At both temperatures the catalyst solubility in the expanded solvent decreases with $\mathrm{CO}_{2}$ addition and catalyst precipitation eventually occurs at a certain expansion level, termed the "maximum homogeneous expansion limit", MHEL. Fig. 9 shows isothermal MHEL curves for the $\mathrm{Co}\left(\right.$ salen*)/ $\mathrm{CH}_{2} \mathrm{Cl}_{2}$ system. The region below the curves represents the homogenous expanded

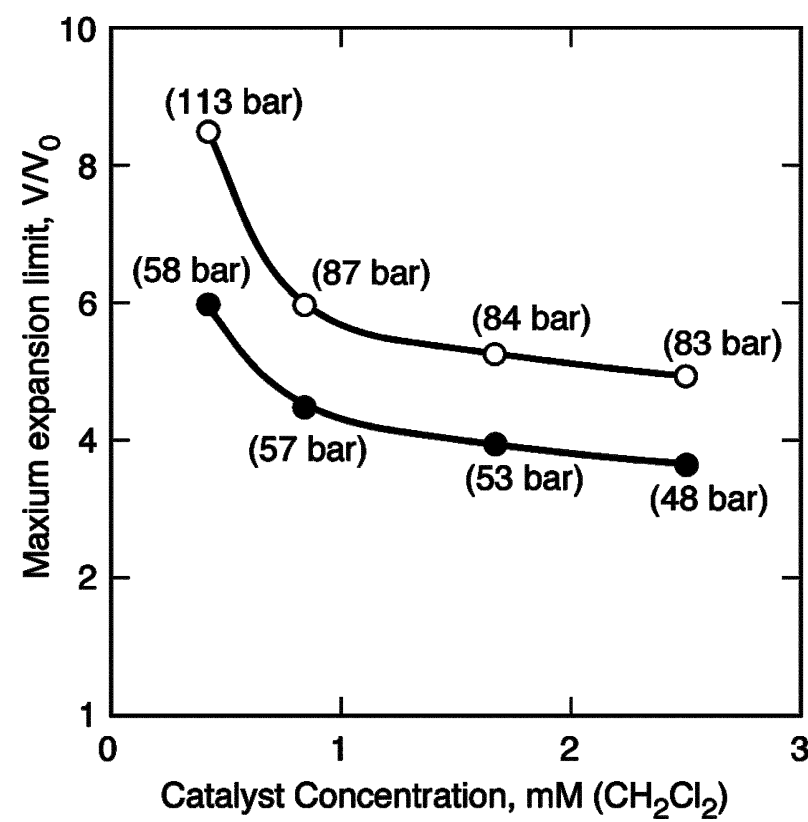

Fig. 9 Maximum limits for homogeneous expansion (MHEL) of $\mathrm{CH}_{2} \mathrm{Cl}_{2}$ + catalyst solutions by $\mathrm{CO}_{2}$ at $25^{\circ} \mathrm{C}(\mathbf{O})$ and $50{ }^{\circ} \mathrm{C}(\mathrm{O})$.

phase available for performing reactions while the region above the curves is suitable for catalyst separation, post reaction. For a given catalyst/solvent combination, the MHEL increases with temperature but decreases with increasing initial catalyst concentration. As shown in Fig. 9, the MHEL at $25^{\circ} \mathrm{C}$ is roughly 5 for the $0.4 \mathrm{mM}$ $\mathrm{CH}_{2} \mathrm{Cl}_{2}$ solution of the $\mathrm{Co}($ Salen*) catalyst and 2.5 for the corresponding $2.5 \mathrm{mM}$ solution. At $50{ }^{\circ} \mathrm{C}$, the MHEL is roughly 4 for the $2.5 \mathrm{mM}$ solution, implying that up to $80 \mathrm{vol} . \%$ of the organic solvent may be replaced by $\mathrm{CO}_{2}$ in the CXL while retaining catalyst solubility. It is noteworthy that the total pressures at the MHEL are tens of bars, as compared to hundreds of bars for $s c \mathrm{CO}_{2}$. MHEL data are clearly essential to define operating conditions both for homogeneous oxidations and for catalyst separation, post reaction.

\section{Enhancement of oxygen solubilities in CXLs}

It has been a matter of contention whether $\mathrm{O}_{2}$ is much more soluble in CXLs than in organic solvents. This issue is important because the concentration, and, therefore, the reactivity of $\mathrm{O}_{2}$ may be critical to the rates and selectivities of catalytic reactions. We previously reported a method for measuring equilibrium $\mathrm{O}_{2}$ concentrations in CXLs. ${ }^{1 b}$ This method is based on directly sampling the expanded phase and the vapor phase, and employing GC/TCD analysis for measuring the $\mathrm{O}_{2}$ concentrations in the two phases. We employed the same technique to measure $\mathrm{O}_{2}$ concentration in liquid $\mathrm{CO}_{2}$. As shown in Fig. 10, the measured oxygen concentrations in liquid $\mathrm{CO}_{2}$ are in excellent agreement with the data from literature, ${ }^{9}$ thus confirming the reliability of our method for measuring $\mathrm{O}_{2}$ concentration in CXLs.

As shown in Fig. 11, the measured $\mathrm{O}_{2}$ mole fraction in the $\mathrm{CO}_{2-}$ expanded $\mathrm{CH}_{2} \mathrm{Cl}_{2}$ liquid phase (at $V / V_{0}=2$ ) increases approximately linearly with the total oxygen content of the system, the values being on the order of hundredths of a mole fraction. These values are about an order of magnitude greater than the $\mathrm{O}_{2}$ solubility in neat $\mathrm{CH}_{2} \mathrm{Cl}_{2}$ (mole fraction $=1 \times 10^{-3}$ at $25^{\circ} \mathrm{C}$ and $\left.1 \mathrm{bar}^{10}\right)$ and are of the same order of magnitude observed for liquid $\mathrm{CO}_{2} \cdot{ }^{9}$ In contrast, the $\mathrm{O}_{2}$ solubility in $\mathrm{CO}_{2}$-expanded $\mathrm{CH}_{3} \mathrm{CN}$ is about two orders of magnitude greater than that in neat $\mathrm{CH}_{3} \mathrm{CN} .{ }^{1 c}$ As shown in Fig. 12, the $\mathrm{O}_{2}$ concentrations also increase linearly upon $\mathrm{CO}_{2}$ addition, reaching $\sim 7-8 \mathrm{~mol} \%$ at expansion levels $(\mathrm{VI}$ $V_{0}$ ) of 7 to 8 . However, such high expansions are not suitable for homogeneous reactions since the catalyst would precipitate from solution. These new results confirm the significant enhancement of 


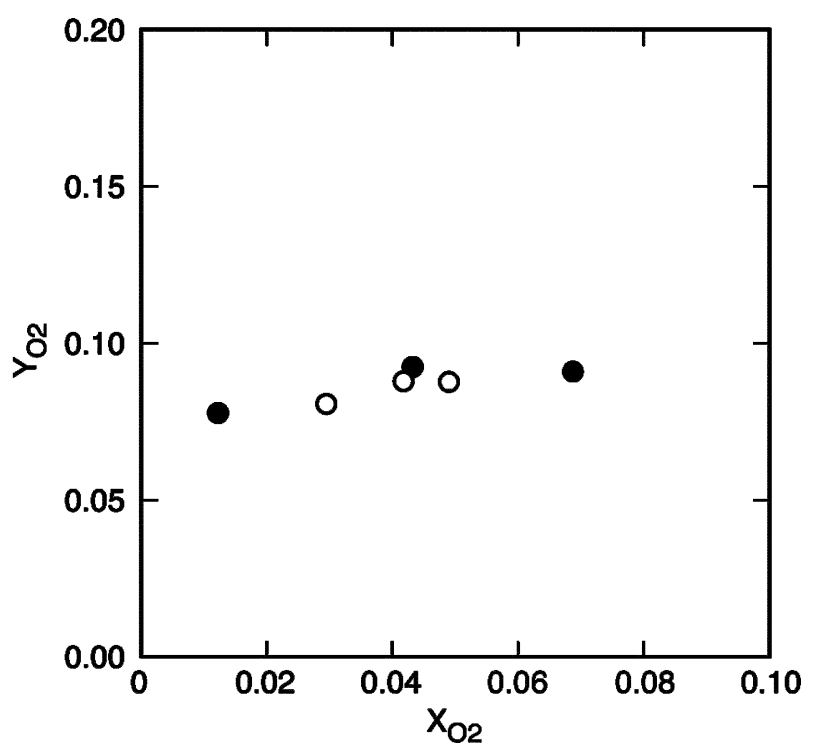

Fig. 10 Comparison of measured solubilities of oxygen in dense $\mathrm{CO}_{2}$ at 25 ${ }^{\circ} \mathrm{C}$; This study (O); Data from Battino et al. ${ }^{9}(\bigcirc)$.

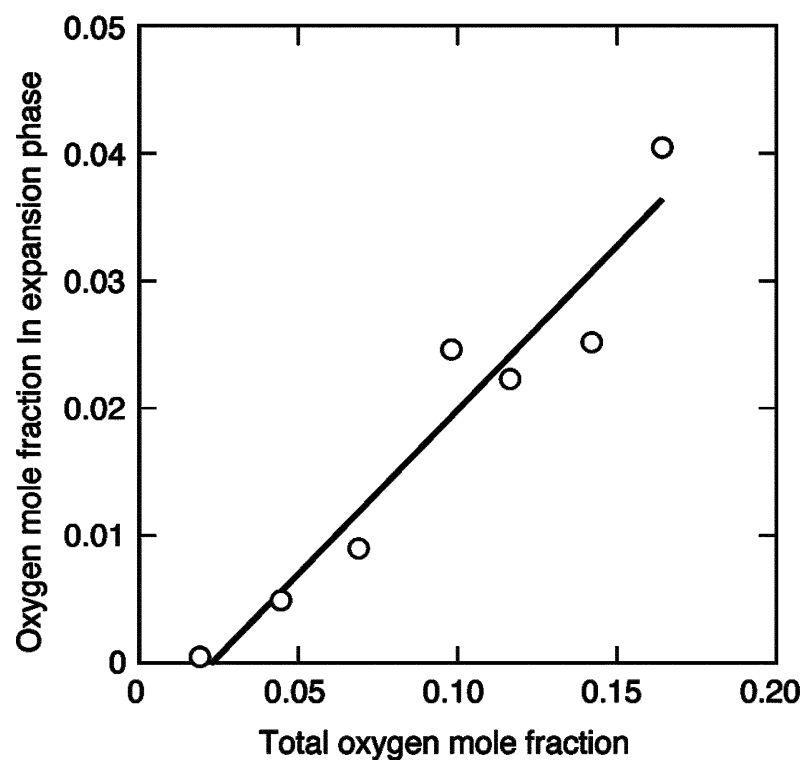

Fig. 11 Variation of $\mathrm{O}_{2}$ mole fraction in $\mathrm{CO}_{2}$-expanded $\mathrm{CH}_{2} \mathrm{Cl}_{2}\left(V / V_{0}=\right.$ 2) as a function of total $\mathrm{O}_{2}$ content in the system $\left(T=30^{\circ} \mathrm{C}\right)$.

$\mathrm{O}_{2}$ solubilities in CXLs compared to the corresponding neat solvents, albeit the enhancement varies depending on the solvent.

\section{Conclusion}

This report demonstrates that continua of $\mathrm{CO}_{2}$-expanded solvents (CXLs), formed by combining organic solvents and $\mathrm{scCO}_{2}$, are excellent media for catalytic oxidation reactions. The $\mathrm{O}_{2}$ oxidation of DTBP to DTBQ with Co(salen*) as the catalyst has been investigated in $\mathrm{CO}_{2}$-expanded solvent media based on $\mathrm{CH}_{3} \mathrm{CN}$ and $\mathrm{CH}_{2} \mathrm{Cl}_{2}$ and the results have been compared with those obtained in $s c \mathrm{CO}_{2}$, and in the neat organic solvents. Reaction rates, as estimated from turnover-frequencies, are increased by as much as two orders of magnitude over that of the reaction in $s c \mathrm{CO}_{2}$ or neat organic solvents, and with comparable selectivity toward the desired oxidation product DTBQ. Thorough evaluation has been made of the effects on reaction rates and product distribution of reaction parameters (oxygen concentration, catalyst concentration, reaction temperature, extent of expansion, choice of solvent). Dependence on these parameters confirms the same general mechanism for the reactions in CXLs as has been described for other media, including $s c \mathrm{CO}_{2}$.

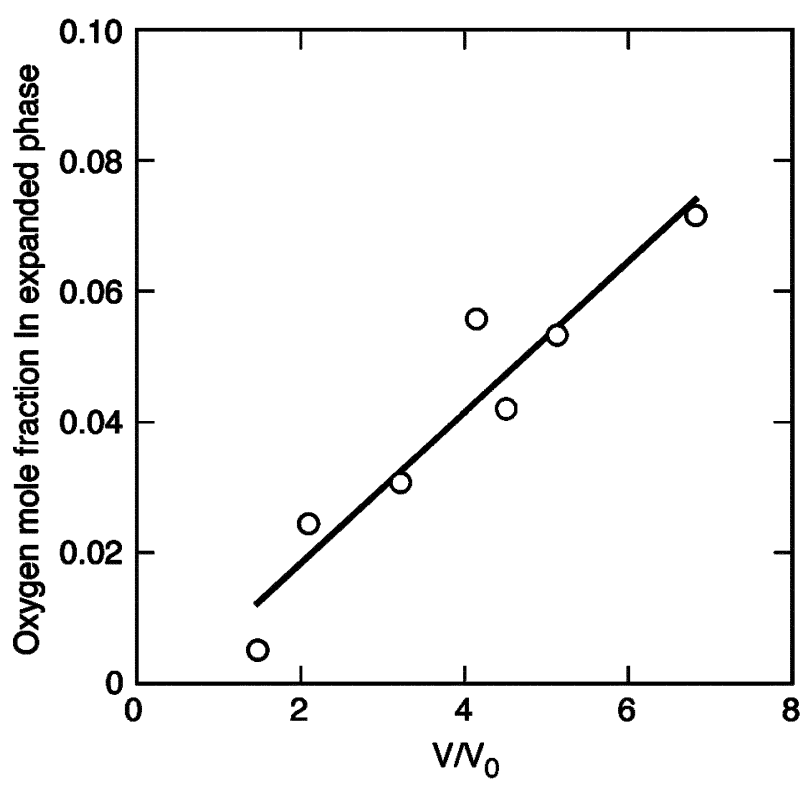

Fig. 12 Variation of $\mathrm{O}_{2}$ concentration in $\mathrm{CO}_{2}$-expanded $\mathrm{CH}_{2} \mathrm{Cl}_{2}$ phase with expansion ratio $\left(T=30^{\circ} \mathrm{C}\right.$; total oxygen mole fraction in the system $=0.11$ ).

The investigation showed that the combination of $\mathrm{CO}_{2}$ and organic solvents facilitates control of the solubilities of two reaction partners, namely the transition metal catalyst and the preferred terminal oxidant, oxygen. The solubility of the catalyst decreases with further addition of $\mathrm{CO}_{2}$. The catalyst can be made to precipitate by adding $\mathrm{CO}_{2}$ in excess of the maximum homogeneous expansion limit, MHEL, which varies with the specific catalyst/ solvent system, the catalyst concentration and the temperature. The oxygen solubility was measured for $\mathrm{CH}_{2} \mathrm{Cl}_{2}$-based CXLs and found to increase with $\mathrm{CO}_{2}$ expansion. In general (2 examples now), the solubility of oxygen in CXLs exceeds that in the corresponding neat organic solvent, by 1 or 2 orders of magnitude, approximating that in liquid $\mathrm{CO}_{2}$.

\section{Acknowledgement}

This research was supported by research grant CHE-9815321 from the National Science Foundation.

\section{References}

1 (a) G. B. Combes, F. Deghani, F. P. Lucien, A. K. Dillow and N. R. Foster, in Reaction Engineering for Pollution Prevention, ed. M. A. Abraham and R. P. Hesketh, Elsevier, Amsterdam, 2000, 173-181; (b) C. A. Thomas, R. J. Bonilla, Y. Huang and P. G. Jessop, Can. J. Chem., 2001, 79, 719-724; (c) P. G. Jessop, R. R. Stanley, R. A. Brown, C. A. Eckert, C. L. Liotta, T. T. Ngo and P. Pollet, Green Chem., 2003, 5, 123-128; (d) G. Musie, M. Wei, B. Subramaniam and D. H. Busch, Coord. Chem. Rev., 2001, 219-221, 789-820; (e) M. Wei, G. T. Musie, D. H. Busch and B. Subramaniam, J. Am. Chem. Soc., 2002, 124(11), 2513-2517; (f) Z. Hou, B. Han, L. Gao, T. Jiang, Z. Liu, Y. Chang, X. Zhang and J. He, New J. Chem., 2002, 9, 1246-1248; ( $g$ ) M. F. Sellin, P. B. Webb and T. J. Cole-Hamilton, Chem. Commun., 2001, 781-782.

2 H. Jin and B. Subramaniam, Chem. Eng. Sci., 2003, 58, 1897-1901.

3 (a) K. W. Hutchenson, in Supercritical Fluid Technology in Materials Science and Engineering, ed. Y-P Sun, Marcel Dekker, New York, 2002; (b) P. G. Jessop, T. Ikariya and R. Noyori, Chem. Rev., 1999, 99, 475-494; Chemical Synthesis Using Supercritical Fluids, ed. P. G. Jessop and W. Leitner, VCH-Wiley, Weinheim, 1999; (c) E. R. Birnbaum, R. M. Le Lacheur, M. Richard, A. C. Horton and W. Tumas, J. Mol. Catal. A, 1999, 139, 11-24; (d) D. R. Pesiri, D. K. Morita, W. Glaze and W. Tumas, Chem. Commun., 1998, 9, 1015-1016; (e) G. R. Haas and J. W. Kolis, Organometallics, 1998, 17, 4454-4460; (f) X.-W. 
Wu, Y. Oshima and S. Koda, Chem. Lett., 1997, 1045-1046; (g) E Sahle-Demessie, M. A. Gonzalez, J. Enriquez and Q. Zhao, Ind. Eng. Chem. Res., 2000, 39, 4858-4864.

4 (a) P. T. Anastas and T. C. Williamson, in Green Chemistry: Designing Chemistry for the Environment, ACS Symposium Series, No: 626, ed. P T. Anastas and T. C. Williamson, Am. Chem. Soc., Washington, D.C., 1996, 1-17; (b) P. T. Anastas and M. M. Kirchhoff, Acc. Chem. Res., 2002, 35, 686-694; (c) P. T. Anastas and J. B. Zimmerman, Env. Sci. Technol., 2003, 37, 94A-101A.

5 I. Kohara, H. Fujiyama, K. Iwai, S. Nishiyama and S. Tsuruya, J. Mol. Catal. A: Chem., 2000, 153(1-2), 93-101; I. G. Kolesnik, E. G Zhizhina and K. I. Matveev, J. Mol. Catal. A: Chem., 2000, 153, 147-154; R. Pathak and G. N. Rao, J. Mol. Catal. A: Chem., 1998, 130(3), 215-220.

6 (a) Y. Deng and D. H. Busch, Inorg. Chem., 1995, 34, 6380-6386; (b) M. Yamada, K. Araki and S. Shiraishi, J. Chem. Soc., Perkin Trans.,
1990, 2687-2701; (c) B. B. Corden, R. S. Drago and R. P. Perito, J. Am Chem. Soc., 1985, 107, 2903-2907; (d) R. S. Drago, J. Gaul, A Zombeck and D. Straub, J. Am. Chem. Soc., 1980, 102, 1033-1038; (e) X.-Y. Wang, R. J. Motekaitis and A. E. Martell, Inorg. Chem., 1984, 22, 271-275.

7 G. Musie, M. Wei, B. Subramaniam and D. H. Busch, Inorg. Chem., 2001, 40, 3336-3341.

8 T. D. Smith and J. R. Pilbrow, Coord. Chem. Rev., 1981, 39, 295-283 R. D. Jones, D. A. Summerville and F. Basolo, Chem. Rev., 1979, 79, 139-179; G. McLendon and E. A. Martell, Coord. Chem. Rev., 1976, 19, 1-39.

9 Solubility Data Series: Volume 7, Oxygen and Ozone, ed. R. Battino, Pergamon Press, Oxford, New York, 1981.

10 J. H. Hildebrand, J. M. Prausnitz and R. L. Scott, Regular and Related Solutions: The Solubility of Gases, Liquids, and Solids, John Wiley, New York, 1970 